\title{
Identification of Mangrove Areas by Remote Sensing: The ROC Curve Technique Applied to the Northwestern Mexico Coastal Zone Using Landsat Imagery
}

\author{
Luis C. Alatorre ${ }^{1,2, *}$, Raquel Sánchez-Andrés ${ }^{3}$, Santos Cirujano ${ }^{3}$, Santiago Beguería ${ }^{4}$ and \\ Salvador Sánchez-Carrillo 5
}

1 División Multidisciplinaría de la UACJ en Cuauhtémoc, Universidad Autónoma de Ciudad Juárez (UACJ), Calle Morelos y privada del Roble núm. 101, Fracc. El Roble, C.P. 31579, Cuauhtémoc, Chihuahua, México

2 Instituto Pirenaico de Ecología, Consejo Superior de Investigaciones Científicas, Zaragoza 50080, Spain

3 Real Jardín Botánico, Consejo Superior de Investigaciones Científicas, Madrid 28014, Spain; E-Mails: rsanchez@rjb.csic.es (R.S.-A.); santos@rjb.csic.es (S.C.)

4 Estación Experimental de Aula Dei, Consejo Superior de Investigaciones Científicas, Zaragoza 50059, Spain; E-Mail: sbegueria@eead.csic.es

5 Museo Nacional de Ciencias Naturales, Consejo Superior de Investigaciones Científicas, Madrid 28006, Spain; E-Mail: sanchez.carrillo@mncn.csic.es

* Author to whom correspondence should be addressed; E-Mail: luis.alatorre@uacj.mx; Tel.: +625-112-17-19; Fax: +625-112-17-19.

Received: 27 April 2011; in revised form: 5 July 2011 / Accepted: 8 July 2011 /

Published: 25 July 2011

\begin{abstract}
In remote sensing, traditional methodologies for image classification consider the spectral values of a pixel in different image bands. More recently, classification methods have used neighboring pixels to provide more information. In the present study, we used these more advanced techniques to discriminate between mangrove and non-mangrove regions in the Gulf of California of northwestern Mexico. A maximum likelihood algorithm was used to obtain a spectral distance map of the vegetation signature characteristic of mangrove areas. Receiver operating characteristic (ROC) curve analysis was applied to this map to improve classification. Two classification thresholds were set to determine mangrove and non-mangrove areas, and two performance statistics (sensitivity and specificity) were calculated to express the uncertainty (errors of omission and commission) associated with the two maps. The surface area of the mangrove category
\end{abstract}


obtained by maximum likelihood classification was slightly higher than that obtained from the land cover map generated by the ROC curve, but with the difference of these areas to have a high level of accuracy in the prediction of the model. This suggests a considerable degree of uncertainty in the spectral signatures of pixels that distinguish mangrove forest from other land cover categories.

Keywords: remote sensing; maximum likelihood algorithm; curve ROC; mangrove; sensitivity/specificity; Gulf of California

\section{Introduction}

Wetlands are valuable ecosystems because they support significant biological diversity and also serve as sources, sinks, and transformers of numerous chemical and biological substances [1]. Mangrove wetlands, which dominate coastal areas of subtropical and tropical regions, are regarded as analogous to tropical rain forests. Both of these ecosystems show significant habitat diversity and ecosystem productivity, and often enhance marine coastal productivity by nutrient export [2].

Mangroves provide tidal control [3], shoreline stabilization [4,5], and serve as habitats for coastal fish and wildlife communities [6,7]. In addition, in many undeveloped and developing countries, mangrove trees are important sources of wood for cooking and heating and for building houses, huts, and fences. Mangrove leaves are used to make matting and the wood is additionally employed as scaffolding. Mangroves also often have significant cultural and medicinal values [8,9].

Unfortunately, there is an alarming global decline in mangrove ecosystems because of population growth, global warming, aquaculture, and industrial and urban development [10-13]. As a result of the monetary costs associated with the loss of mangrove ecosystems, policymakers are becoming increasingly aware of the need to incorporate new methods to quickly and accurately assess changes in mangrove forest cover. Such efforts are intended to improve integrated coastal zone management, a process initiated at the 1992 Earth Summit [14]. According to the most recent mangrove resource assessment, about $170,000 \mathrm{~km}^{2}$ of mangrove ecosystems remain worldwide, and an average of about $1,030 \mathrm{~km}^{2}$ per year was lost from 1990 to 2000 [15].

Methods for determining the extent and spatial distribution of mangrove forests have improved over time because of advances in technologies such as remote sensing (RS), global positioning systems (GPS), and geographic information systems (GIS). RS is a powerful tool for analyzing estuaries and coastal systems and is ideal for monitoring the spatial and temporal evolution of the mangrove ecosystems because it is cost-effective, time-efficient, and non-invasive. It allows for a high intensity of measurements in relatively inaccessible and sensitive sites. Data from multispectral satellite sensors such as SPOT (Système Pour l'Observation de la Terre), the Landsat Thematic Mapper (TM), and the Enhanced Thematic Mapper Plus (ETM+) provide useful sources of remotely-sensed data and readily allow discrimination of mangrove from adjacent non-mangrove regions [16-19].

In particular, multi-band spectral data (typically red and near-infrared [NIR] wavelengths) can be used to identify vegetation based on spectral reflectance. Remotely sensed spectral differences correlate with biophysical properties of the mangrove canopy. In particular, numerous studies have 
shown that mangrove normalized difference vegetation index (NDVI) values correlate with biomass, canopy cover, and leaf area index (LAI) [20-25]. Other studies have utilized RS data to analyze the relationship between changes in coastal land use and mangrove distribution [26-32] and to characterize changes in wetland vegetation with alterations in areal coverage $[33,34]$. In general, most mangrove studies have focused on the biology and ecology of mangroves, and on factors that influence productivity, biodiversity, and geographical distribution [35].

Mexico has suffered significant mangrove deforestation since 1980 because of growth in aquaculture [36]. Mexico is estimated to have suffered a $2.1 \%$ annual loss of mangroves from 1990-2000, just below that of the USA (2.4\%) and Nicaragua (2.8\%), but far less than seen in Haiti, Barbados, and Honduras, where deforestation rates are greater than $4 \%$ annually. Recent data reported by the FAO (Food and Agriculture Organization of the United Nations), based on numerous sources, showed that Mexico had the highest rate of mangrove deforestation in the Middle American region, with losses of more than $100 \mathrm{~km}^{2}$ per year [11]. Several studies commencing in the mid-1990s used satellite images to estimate the spatial extent of mangroves in Mexico, but the results remain controversial because of methodological problems [11]. The National Forest Inventory of 2000 (INF2000) standardized RS techniques and implemented partial verification methods to increase the accuracy of cover type estimates. However, INF-2000 did not consider mangrove forests, so the extent of changes in mangrove ecosystems remains controversial [11].

Estimates of mangrove cover by use of RS have been performed only in a few local regions, mainly in northwestern Mexico [37]. Only a small number of studies have assessed the spatial distribution of mangrove forests at the regional level $\left(100-10,000 \mathrm{~km}^{2}\right)$, because of lack of field verification.

The aim of the present study was to use recently developed RS technologies to determine the extent of mangrove forest coverage. Our methods involved traditional RS techniques (supervised classification), the implementation of a Receiver Operating Characteristic (ROC) curve to select a classification threshold, and assessment of uncertainties associated with our predictions. This approach has been successfully used in a badlands landscape in the Ésera River catchment (Spanish Pyrenees) to identify areas with erosion and areas at risk of erosion following small changes in the nature and amount of vegetation cover [38]. Mangrove forest degradation can commence as a self-thinning process [39], and our methods thus sought to detect areas where vegetation cover had diminished. Ultimately, our techniques could be used to construct large-scale national forest inventories and to assess changes in mangrove ecosystems over time.

\section{Study Area}

This study was performed in northwestern Mexico, along a $509 \mathrm{~km}$ stretch of the eastern coast of the Gulf of California (Figure 1), an area of about 5,000 $\mathrm{km}^{2}$. This region includes mangrove wetlands associated with the Quaternary progradation deltas of the Yaqui, Mayo, and Fuerte Rivers and is the largest wetland extension of the Mexican northwest. The climate of the area is warm and dry, with a mean annual temperature of $24^{\circ} \mathrm{C}$ (range $16-48{ }^{\circ} \mathrm{C}$ ) and rainfall is less than $300 \mathrm{~mm} \mathrm{y}^{-1}$. 
Figure 1. Location of the study area (a composite of four Landsat scenes). Inset: location of mangrove communities in the Gulf of California.

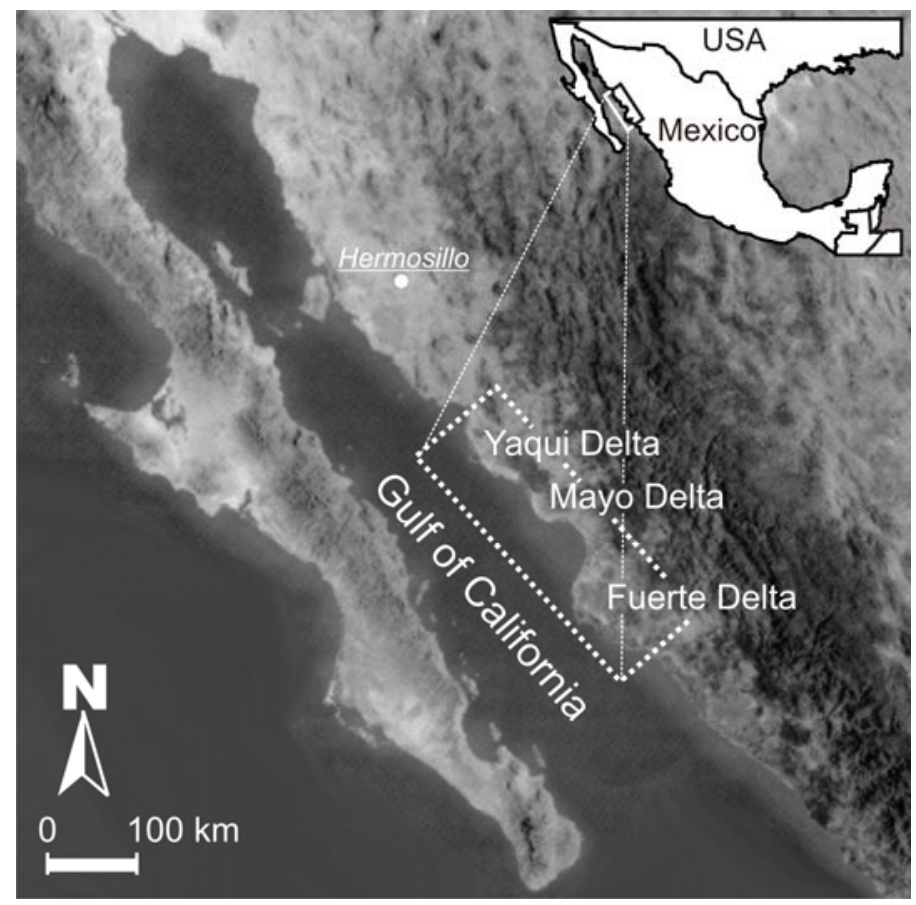

Mangrove wetlands are mainly mixed stands of Rhizophora mangle, Avicennia germinans, and Laguncularia racemosa. Rhizophora mangle is principally restricted to the shoreline areas of lagoons and occurs in association with patches of pickleweed (Salicornia virginica and Batis maritima) in small and very shallow pools. Most mangrove wetlands are surrounded by shrimp farms, which are believed to have significantly modified or destroyed mangrove forests since 1985 [2]. Such farms are the main commercial activity in this area, because ocean fisheries have been severely overexploited.

\section{Data and Methods}

\subsection{Data Selection and Preparation}

Satellite images can be adversely affected by radiometric interference from solar radiation and particular atmospheric conditions. In images with high temporal and low spatial resolution (e.g., NOAA-AVHRR), this problem is usually resolved by the use of multi-temporal compound images and filtration. In the case of images with low temporal frequency (e.g., Landsat), it is necessary to use more complex correction methodologies.

In this study we employed a database of Landsat ETM+ (30-m spatial resolution) from October 2001 (corresponding to late "summer" in our study region) because of the low cloud cover during this month (Figure 1). Table 1 shows the dates of the images used in each time series. The images were geometrically corrected using control points and the algorithm developed by Palá and Pons [40] implemented in the Miramon software. This procedure controls for topographic distortion by employing a digital terrain model (DTM), database of the INEGI (National Institute of Statistic and Geography), with $30 \mathrm{~m}$ spatial resolution [41]. 
Table 1. Dates of the Landsat ETM+ images used in the present study.

\begin{tabular}{ccccc}
\hline & & & \multicolumn{2}{c}{ Coordinates UTM 12n } \\
Date & Sensor & Path/Row & Xmin/Xmax & Ymin/Ymax \\
\hline $26 / 09 / 2004$ & ETM+ & $35 / 41$ & $378836 / 627698$ & $2925339 / 3143530$ \\
$26 / 10 / 2004$ & ETM+ & $34 / 41$ & $532793 / 776867$ & $2927049 / 3143763$ \\
$08 / 10 / 2004$ & ETM+ & $34 / 42$ & $608574 / 710205$ & $2809971 / 2974131$ \\
$14 / 10 / 2004$ & ETM+ & $33 / 42$ & $667113 / 788780$ & $2783238 / 2853662$ \\
\hline
\end{tabular}

Atmospheric effects were corrected by use of the radiative transfer code $6 \mathrm{~S}$ [42], described in detail by Vicente-Serrano and colleagues [43]. Areas affected by clouds in corrected images were identified by visual inspection and were eliminated by mean of manual digitalization of these areas.

\subsection{Classification Procedure}

\subsubsection{Definition of the Thematic Categories and Training Areas}

An important objective was to define areas of Landsat images that represented thematic categories as determined by maximal spectral heterogeneity. Thus, to identify mangrove areas, it was necessary for the classification algorithm to establish a priori categories that adequately represented the variability of land cover types in the study area. Our maximum likelihood algorithm considers the average characteristics of the spectral signature of each category and the covariance among all categories, thus allowing for precise discrimination of categories.

Figure 2. Training samples used to establish thematic categories, and to select training areas for each category, in accordance with the criteria proposed by Cintron et al. [44]: (i) mangrove forest; (ii) mangrove forest with pickleweed; (iii) pickleweed; (iv) scattered vegetation; (v) bare soil; (vi) very shallow water; and (vii) open water.

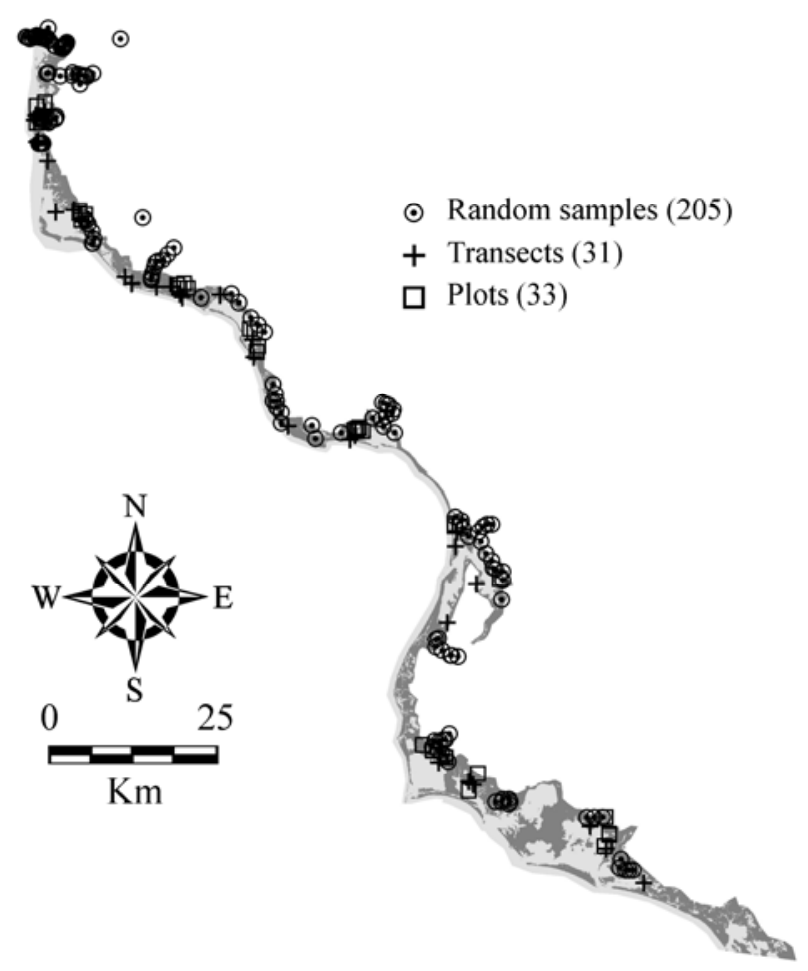


Field observations and training samples were used to establish thematic categories, and to select training areas for each category. The structure of mangrove forests and the other categories were obtained using random sample points, field transects and equidistant $10 \mathrm{~m}^{2}$ plots around the experimental sites, in accordance with the criteria proposed by Cintron et al. [44] (Figure 2). A spectral signature and contingency matrix generated using ERDAS 8.7 software were used to determine the extent of discrimination among categories.

\subsubsection{Image Classification and Validation}

Image classification was based on the maximum likelihood method, employing the set of thematic categories. The discriminatory capacity of the classification model was determined by the use of a confusion matrix established with the training samples. After verification of such samples, a spectral distance map was obtained for the mangrove category. This map represents the distance between the spectral signature of each pixel and that of the mangrove category, and considers the variance-covariance matrix of all spectral signatures.

Based on the spectral distance map, maps of mangrove and non-mangrove areas were prepared by the establishment of a classification threshold. Determination of the classification threshold for construction of the map was based on the ROC curve, a method derived from signal detection theory, that has been widely used in environmental sciences [38,45-46]. The ROC curve for each classification is determined by calculating the sensitivity and specificity:

$$
\begin{aligned}
& \text { sensitivity }=\frac{a}{a+c} \\
& \text { specificity }=\frac{d}{b+d}
\end{aligned}
$$

where $a$ represents true positives, $d$ true negatives, $b$ false positives, and $c$ false negatives (Table 2).

Table 2. Confusion matrix, with $Y_{1}$ belonging to class $Y$, and $Y_{0}$ not belonging to class $Y$. $a$ represents true positives; $d$ represents true negatives; $b$ represents false positives (type I error); and $c$ represents false negatives (type II error).

\begin{tabular}{cccc}
\hline & & \multicolumn{2}{c}{ Observed } \\
\cline { 3 - 4 } & & $\boldsymbol{Y}_{\boldsymbol{1}}$ & $\boldsymbol{Y}_{\boldsymbol{0}}$ \\
\hline \multirow{2}{*}{ Predicted } & $Y^{\prime}{ }_{1}$ & $a$ & $b$ \\
& $Y^{\prime}{ }_{0}$ & $c$ & $d$ \\
\hline
\end{tabular}

The sensitivity of the model is the proportion of positive pixels correctly predicted, (i.e., the probability that a pixel belonging to a particular category is correctly identified). The specificity of the model is the proportion of negative pixels correctly predicted (i.e., the probability that a pixel not belonging to a particular category is correctly identified). Thus, models with high sensitivity can correctly predict positive pixels (pixels belonging to the category of interest) and models with high specificity can correctly predict negative pixels (pixels not belonging to the category of interest). High sensitivity is usually associated with poor specificity, which manifests as an overestimate of area in the category of interest. 
The sensitivity and specificity provide information on the degree of uncertainty in a classification. In other words, "1-sensitivity" and "1-specificity" represent the probabilities of committing an error of omission (type II error, or false negative) or an error of commission (type I error, or false positive), respectively (Table 2). Other common statistics of the classification model, such as the overall reliability,

$$
\text { reliability }=\frac{a+d}{a+b+c+d}
$$

are biased estimates that depend on the proportion of pixels actually belonging to each class, and therefore should not be used for comparison between different case studies (see [38]).

An optimum classification model would be one with the highest possible value of both sensitivity and specificity, minimizing omission and commission errors at the same time. Since this ideal situation is usually not the case, there is a need to make a compromise, and the ROC curve is the optimum tool to make such a choice $[47,48]$. The ROC curve method provides a way to select an optimal model and to discard suboptimal ones independently from the class distribution, based on the uncertainty associated with a specific classification threshold. The sensitivity and specificity pair allows the practitioner to balance the risk associated to both types of errors - omission and commission — for a given classification threshold, and thus choose the most appropriate model for a given application. In this case, for identification of the mangrove areas, a classification threshold was set as the spectral distance for which the sensitivity of the model was 0.9 , corresponding to a $10 \%$ probability of an omission error. For identification of non-mangrove areas, a classification threshold was set as the spectral distance for which the omission and commission errors were approximately equal (about $25 \%$ ). These values were chosen arbitrarily as an example, and other values could be equally valid. What is important is that the ROC curve analysis can be used to explicitly estimate the omission and commission errors associated to the classification model, thus allowing choosing the classification threshold according to the risks associated to both errors.

\section{Results and Discussion}

\subsection{Selection of Categories and Training Areas}

The definition of thematic categories and selection of training areas were based on field observations and training samples (Figure 2). There were seven thematic categories: mangrove forest, mangrove forest with pickleweed, pickleweed, scattered vegetation, bare soil, very shallow water, and open water. The training areas were used to obtain spectral signatures for each thematic category (Figure 3). Bare soils had high signals in all spectral bands, and relatively large variability within each band. In contrast, open water had the lowest average reflectivity.

Discrimination of the different spectral signatures was good for all categories. Bands 3 and 4 were very important in discrimination of vegetation. For vegetated areas, radiation in ETM + band 3 $(0.58-0.68 \mu \mathrm{m})$ is strongly absorbed by chlorophyll, whereas radiation in ETM+ band 4 (0.73 to $1.10 \mu \mathrm{m})$ is strongly reflected [35,49]. Thus, mangrove forests have the highest values in band 4 and the lowest values in band 3 . 
Figure 3. Spectral signature of each thematic class. Vertical bars indicate standard deviations of average reflectivity.
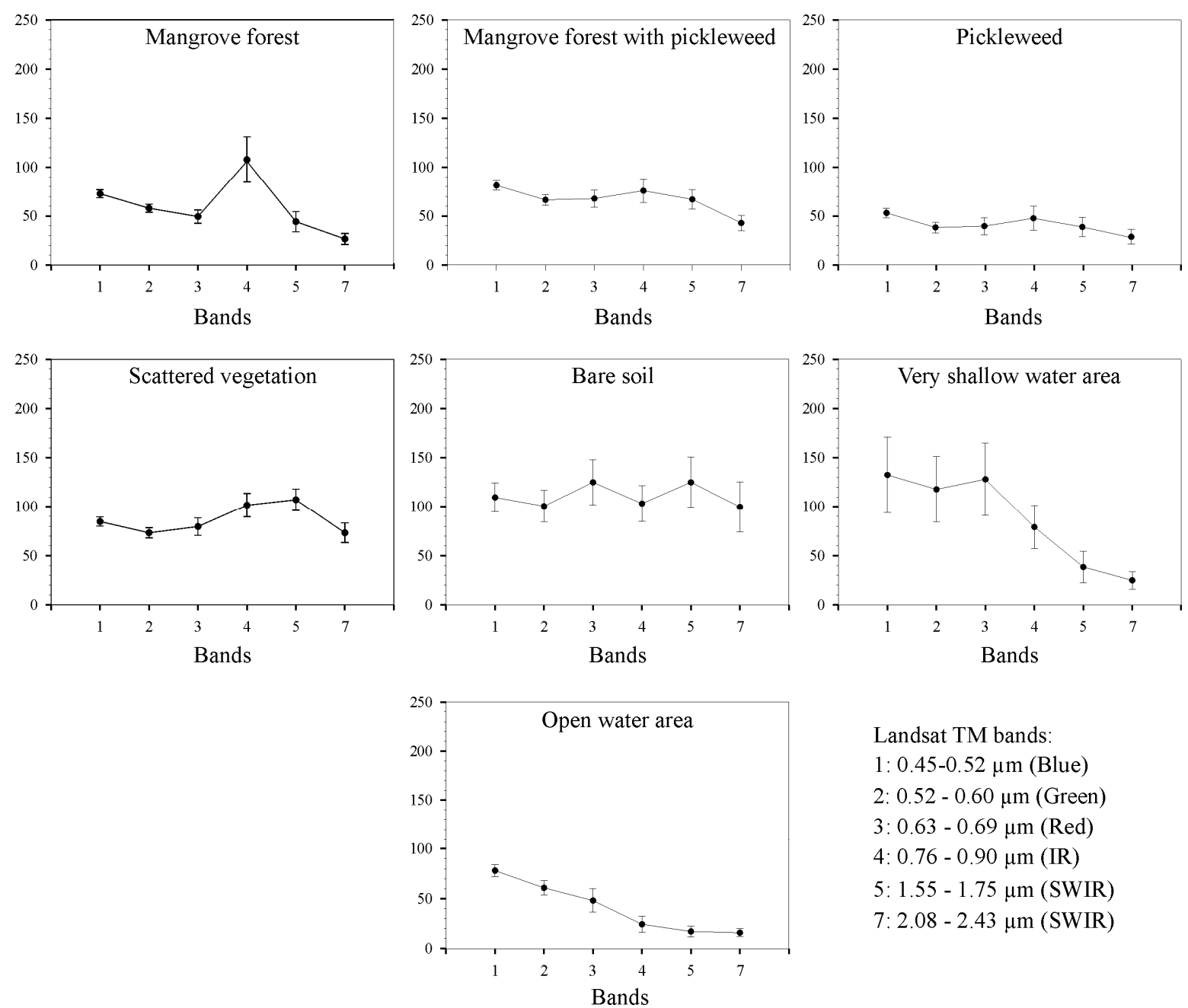

Landsat TM bands:

1: 0.45-0.52 $\mu \mathrm{m}$ (Blue)

2: $0.52-0.60 \mu \mathrm{m}$ (Green)

3: $0.63-0.69 \mu \mathrm{m}$ (Red)

4: $0.76-0.90 \mu \mathrm{m}(\mathrm{IR})$

5: $1.55-1.75 \mu \mathrm{m}$ (SWIR)

7: $2.08-2.43 \mu \mathrm{m}$ (SWIR)

Table 3. Contingency matrix of the classification algorithm, applied to the training sample (proportion and total number of pixels of the class sample).

\begin{tabular}{|c|c|c|c|c|c|c|c|c|c|}
\hline & $\begin{array}{l}\text { Observed } \\
\text { categories }\end{array}$ & $\begin{array}{c}\text { Mangrove } \\
\text { forest }\end{array}$ & $\begin{array}{l}\text { Mangrove } \\
\text { forest with } \\
\text { pickleweed }\end{array}$ & Pickleweed & $\begin{array}{l}\text { Scattered } \\
\text { vegetation }\end{array}$ & $\begin{array}{l}\text { Bare } \\
\text { soil }\end{array}$ & $\begin{array}{c}\text { Very } \\
\text { shallow } \\
\text { water area } \\
\end{array}$ & $\begin{array}{l}\text { Open } \\
\text { water } \\
\text { area }\end{array}$ & $\begin{array}{c}\text { Total } \\
\text { (pixels) }\end{array}$ \\
\hline \multirow{7}{*}{ 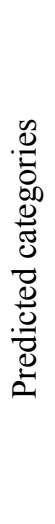 } & Mangrove forest & 0.81 & 0.12 & 0.07 & 0.00 & 0.00 & 0.00 & 0.00 & 864 \\
\hline & $\begin{array}{l}\text { Mangrove forest } \\
\text { with pickleweed }\end{array}$ & 0.10 & 0.78 & 0.15 & 0.04 & 0.00 & 0.00 & 0.00 & 551 \\
\hline & Pickleweed & 0.07 & 0.05 & 0.75 & 0.08 & 0.03 & 0.00 & 0.00 & 566 \\
\hline & $\begin{array}{l}\text { Scattered } \\
\text { vegetation }\end{array}$ & 0.00 & 0.02 & 0.01 & 0.79 & 0.06 & 0.00 & 0.00 & 749 \\
\hline & Bare soil & 0.00 & 0.01 & 0.00 & 0.09 & 0.91 & 0.05 & 0.01 & 1,589 \\
\hline & $\begin{array}{l}\text { Very shallow } \\
\text { water area }\end{array}$ & 0.01 & 0.01 & 0.01 & 0.00 & 00.0 & 0.83 & 0.04 & 465 \\
\hline & Open water area & 0.01 & 0.01 & 0.01 & 0.00 & 0.00 & 0.12 & 0.95 & 3,349 \\
\hline
\end{tabular}

The contingency matrix obtained for the sampling areas, based on the maximum likelihood classification algorithm, showed that all categories had a $75 \%$ success rate (Table 3 ). For mangrove 
areas, confusion levels of $10 \%$ and $7 \%$ were found for mangrove forest with pickleweed, and pickleweed alone, respectively. This confirms the uncertainty associated with identifying areas transitional between pickleweed and mangrove forest.

\subsection{Thematic Classification}

We obtained a land cover map from the classification algorithm by use of the maximum probability classification rule (Figure 4). The validation provided from the use of independent training samples showed good overall reliability $(84.10 \%)$. Discrimination of the pickleweed category was the poorest, with a commission error of $33 \%$ (sensitivity $=0.822$; specificity $=0.670$; see Table 4 ). Discrimination of the very shallow water category was best, with a commission error of only $4 \%$. The classification model had an omission error of $13 \%$ for the mangrove category (sensitivity $=0.871$ ), but classification of the mangrove forest involved some transition areas between pickleweed and mangrove forest that were incorrectly classified, resulting in a commission error of $23 \%$ (specificity $=0.770$ ).

The area occupied by each category was: mangrove forest $488 \mathrm{~km}^{2}$, mangrove forest with pickleweed $228 \mathrm{~km}^{2}$, pickleweed $257 \mathrm{~km}^{2}$, scattered vegetation $428 \mathrm{~km}^{2}$, bare soil $949 \mathrm{~km}^{2}$, very shallow water $108 \mathrm{~km}^{2}$, and open water 2,350 km (Figure 5). Our results indicate that pickleweed areas bordered upon mangrove forest areas (see Figure 4), suggesting a gradual transition between these two types of vegetation. Pickleweed has a high salt tolerance, and occurs in areas along channels where natural berms have formed from sedimentation, and in high marsh plains. Both of these areas have saline soils because of water evaporation in summer and limited freshwater inflow $[2,50]$.

Figure 4. Land cover map based on supervised classification using the maximum likelihood method and the maximum probability classification rule.

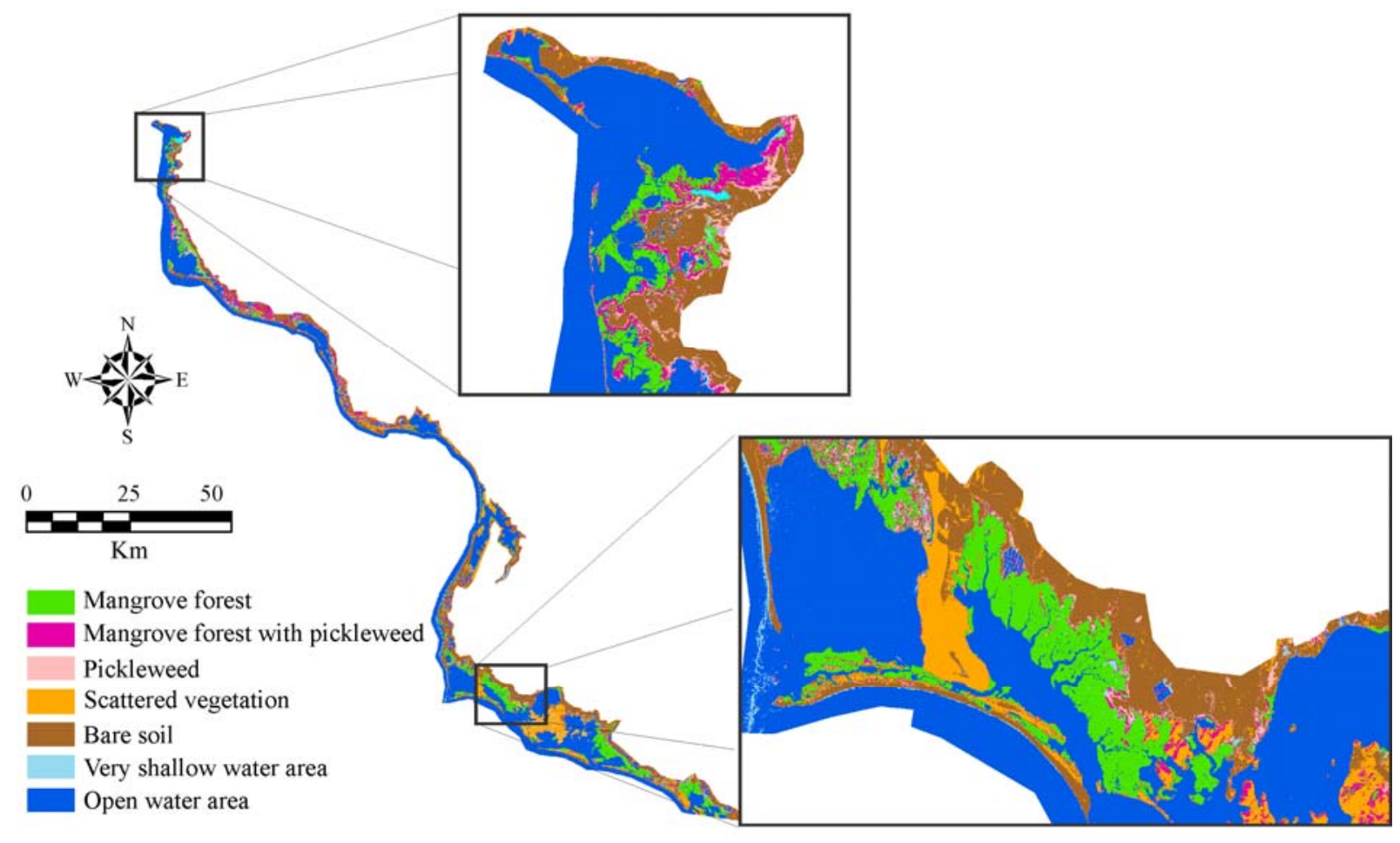


Table 4. Confusion matrix between categories (proportion and total number of pixels), omission errors, commission errors, sensitivity, and specificity.

\begin{tabular}{|c|c|c|c|c|c|c|c|c|c|c|c|}
\hline & $\begin{array}{l}\text { Observed } \\
\text { categories }\end{array}$ & $\begin{array}{c}\text { Mangrove } \\
\text { forest }\end{array}$ & $\begin{array}{l}\text { Mangrove } \\
\text { forest with } \\
\text { pickleweed }\end{array}$ & Pickleweed & $\begin{array}{l}\text { Scattered } \\
\text { vegetation }\end{array}$ & $\begin{array}{l}\text { Bare } \\
\text { soil }\end{array}$ & $\begin{array}{c}\text { Very } \\
\text { shallow } \\
\text { water } \\
\text { area }\end{array}$ & $\begin{array}{l}\text { Open } \\
\text { water } \\
\text { area }\end{array}$ & $\begin{array}{c}\text { Total } \\
\text { (pixels) }\end{array}$ & $\begin{array}{c}\text { Commission } \\
\text { error (\%) }\end{array}$ & Specificity \\
\hline \multirow{10}{*}{ 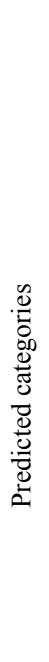 } & Mangrove forest & 0.87 & 0.09 & 0.08 & 0.00 & 0.00 & 0.06 & 0.01 & 95 & 23 & 0.770 \\
\hline & $\begin{array}{l}\text { Mangrove forest } \\
\text { with pickleweed }\end{array}$ & 0.03 & 0.75 & 0.1 & 0.00 & 0.00 & 0.00 & 0.01 & 36 & 14 & 0.860 \\
\hline & Pickleweed & 0.10 & 0.16 & 0.82 & 0.02 & 0.05 & 0.00 & 0.00 & 52 & 33 & 0.670 \\
\hline & $\begin{array}{l}\text { Scattered } \\
\text { vegetation }\end{array}$ & 0.00 & 0.00 & 0.00 & 0.86 & 0.11 & 0.00 & 0.00 & 132 & 11 & 0.890 \\
\hline & Bare soil & 0.00 & 0.00 & 0.00 & 0.12 & 0.84 & 0.00 & 0.00 & 264 & 12 & 0.880 \\
\hline & $\begin{array}{l}\text { Very shallow water } \\
\text { area }\end{array}$ & 0.00 & 0.00 & 0.00 & 0.00 & 0.00 & 0.80 & 0.04 & 12 & 4 & 0.960 \\
\hline & Open water area & 0.00 & 0.00 & 0.00 & 0.00 & 0.00 & 0.14 & 0.94 & 78 & 14 & 0.860 \\
\hline & & & & & & & & & Total & 15.86 & 0.841 \\
\hline & Omission error $(\%)$ & 0.13 & 0.25 & 0.18 & 0.14 & 0.16 & 0.20 & 0.06 & 0.16 & & \\
\hline & Sensitivity & 0.871 & 0.750 & 0.822 & 0.860 & 0.836 & 0.800 & 0.940 & 0.840 & & \\
\hline
\end{tabular}

Figure 5. Estimated coverage $\left(\mathrm{km}^{2}\right)$ of each category in the study area.

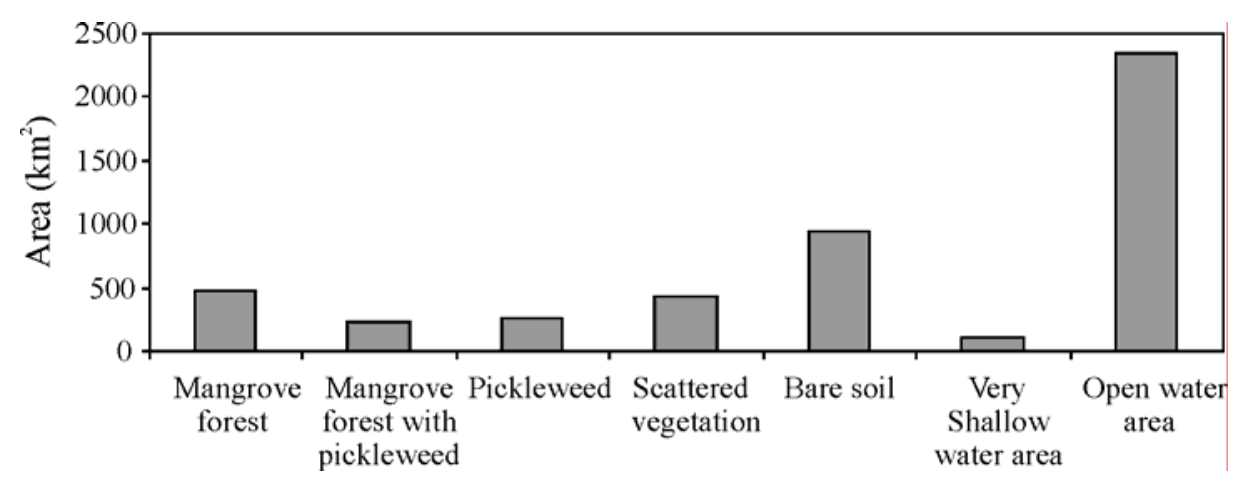

\subsection{Maps of Mangrove and Non-Mangrove Areas}

The land cover classification (described above) confirmed the validity of the spectral categories determined during the supervised phase. Thus, we identified mangrove and non-mangrove areas by use of the spectral distance to the mangrove category map (Figure 6). The spectral distance map is an intermediate requirement in the process of supervised classification, and is used to assign each pixel to the category of greatest similarity (least spectral distance).

However, the main focus of our study was on the mangrove category, and we thus obtained a more precise result using the map of spectral distance in conjunction with a user-determined classification threshold. Spectral distance, as determined by the maximum likelihood method, does not employ linear or Euclidean distance between the centers of spectral signatures. Rather, spectral distance is based on the variance/covariance matrix of all spectral signatures, and thus provides a much more precise distance statistic [38]. 
Figure 6. Spectral distance map (UD: digital units) of the mangrove class in relation to other classes.

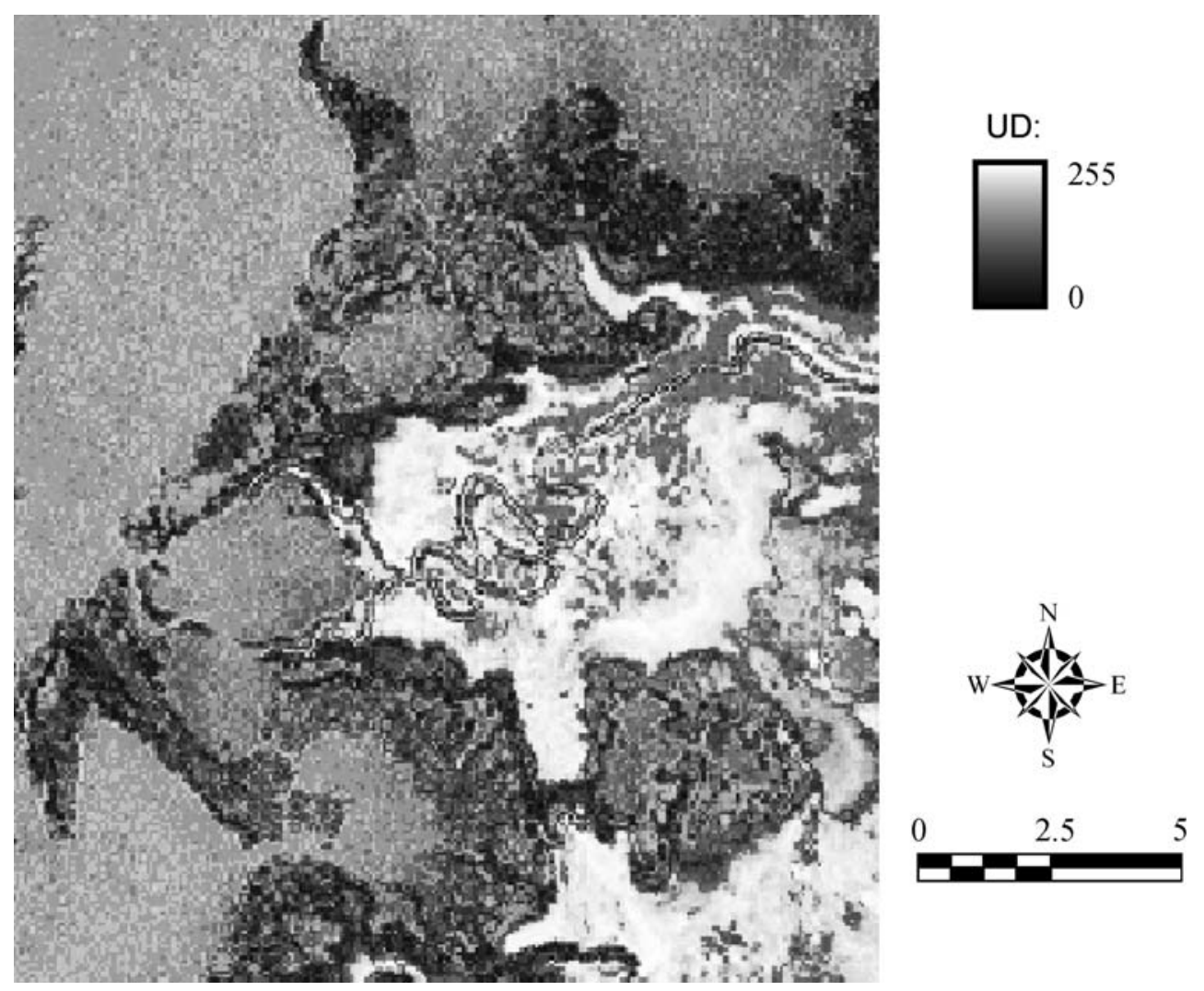

The ROC curve for the mangrove area had a medium-to-high discrimination capacity (Figure 7). This curve shows the sensitivities and specificities associated with different possible values of the classification threshold. Determination of the classification threshold requires a compromise between sensitivity and specificity, because both cannot be maximized simultaneously. Thus, a highly sensitive classification threshold (i.e., with a very low omission error) is associated with moderate specificity, and will lead to overestimation of wetland areas. An underestimation of wetland areas would be obtained using a highly specific threshold.

Thus, we selected a model with a high specificity ( 0.900 , equivalent to selection of a confidence level $\alpha=0.1$ ) to minimize commission errors (false positives). For the spatial discrimination of non-mangrove areas, a classification threshold value was chosen that resulted in approximately equal values for sensitivity $(0.723)$ and specificity $(0.710)$.

We applied both classification thresholds to the map of spectral distance for the mangrove category, and produced maps for mangrove and non-mangrove areas (Figure 8). The maps show that the mangrove area was $466 \mathrm{~km}^{2}$ and the non-mangrove area $4,357 \mathrm{~km}^{2}$. The mangrove area was slightly lower than that from the land cover map generated by the maximum likelihood classification method (see Figures 4 and 8), but our newer model had a higher specificity. 
Figure 7. ROC curve for classification of mangrove areas. The diagonal dashed line represents a model with no predictive ability. Greater deviation of the ROC curve from this diagonal indicates greater discriminatory capacity of the model. U1 and U2 indicate the classification thresholds selected for assessment of mangrove and non-mangrove areas, respectively.

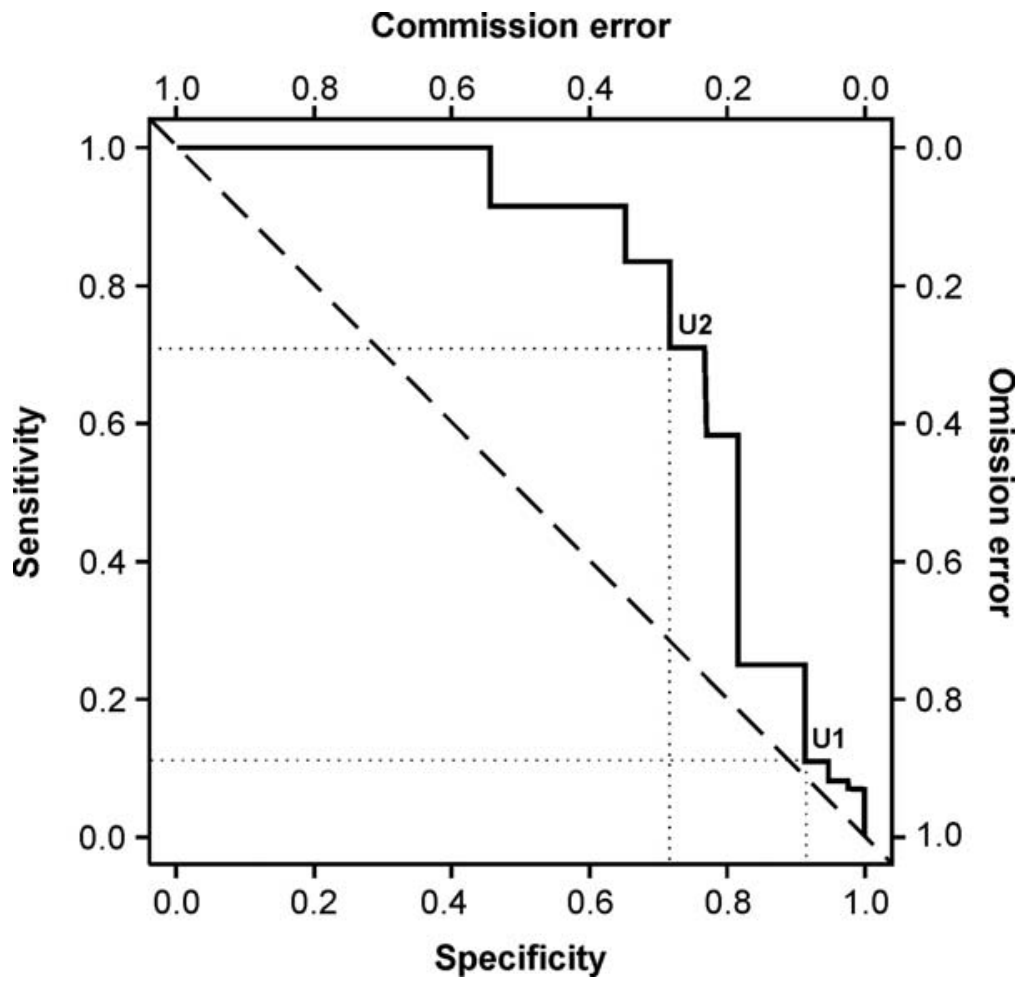

Figure 8. Maps of mangrove and non-mangrove areas obtained from the spectral distance map and the classification threshold.

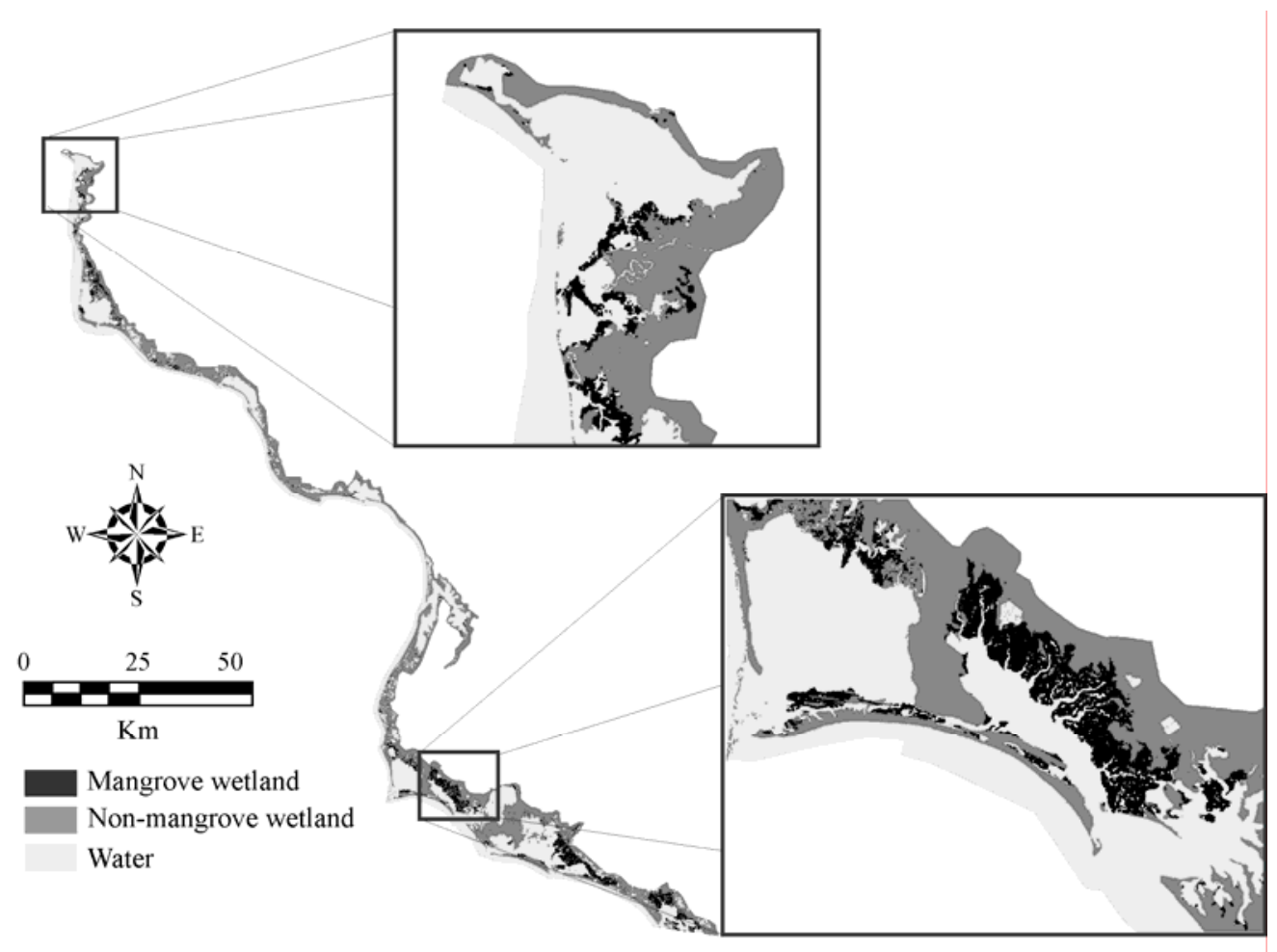




\section{Conclusions}

This study has demonstrated the utility of RS data in basic and applied research to classify mangrove ecosystems at a regional scale $\left(10-10,000 \mathrm{~km}^{2}\right)$ in the Gulf of California of northwestern Mexico. The use of a supervised classification method using the maximum likelihood algorithm with a set of a priori categories allowed us to reliably map mangrove areas. Selection of training areas enabled identification of areas in each category based on maximum variability of spectral signatures. The use of an independent set of randomly selected pixels allowed validation of the classification model ( $84 \%$ overall accuracy).

We used an ROC curve to assess uncertainty in the classification model (based on omission and commission errors), allowing the classification of thresholds for mangrove and non-mangrove areas. The main advantages of this methodology are that it allows precise determination of uncertainties involved in classification, and permits selection of a classification threshold according to the uncertainty level assumed for a specific application. Our method indicated that $466 \mathrm{~km}^{2}$ of the total surface area was occupied by mangrove forests, whereas the supervised maximum likelihood method estimated this area as $488 \mathrm{~km}^{2}$. This suggests a high degree of uncertainty in the spectral signatures of pixels separating mangrove forest from other categories. In particular, pickleweed areas bordering mangrove forest may have constituted transition zones between non-mangrove areas and mangrove areas, where soil is poorly covered by vegetation (approximately $50 \%$ cover).

Finally, we believe that to reduce uncertainty in the identification of mangrove areas and to prepare reliable geographic inventories, it is necessary to compare results from independent research groups who all work with the same dataset and criteria, but employing various techniques. Comparison of such results will permit reduction in discrepancies and the production of Figures, with associated confidence intervals, that can be universally adopted.

\section{Acknowledgments}

This research was supported by the Mexican Secretary of Environment and Natural Resources (SEMARNAT) and the National Council for Science and Technology (CONACYT) by the grant SEMARNAT-2002-C01-0147. R. Sánchez-Andrés is granted by a CSIC-JAEDoc contract and L.C. Alatorre was supported by a scholarship from The National Council for Science and Technology of Mexico (CONACYT).

\section{References}

1. Costanza, R.; d'Arge, R.; de Groot, R.; Farber, S.; Grasso, M.; Hannon, B.; Limburg, K.; Naeem, S.; O'Neil, R.V.; Paruelo, J.; et al. The value of the world's ecosystem services and natural capital. Nature 1997, 387, 253-260.

2. Sánchez-Carrillo, S.; Sánchez-Andrés, R.; Alatorre, L.C.; Angeler, D.G.; Álvarez-Cobelas, M.; Arreola-Lizárraga, J.A. Nutrient fluxes in a semi-arid microtidal mangrove wetland in the Gulf of California. Estuar. Coast. Shelf Sci. 2009, 82, 654-662.

3. Varnell, L.M.; Evans, D.A.; Havens, K.J. A geomorphological model of intertidal cove marshes with application to wetlands management. Ecol. Eng. 2003, 19, 339-347. 
4. Lee, H.Y.; Shih, S.S. Impacts of vegetation changes on the hydraulic and sediment transport characteristics in Guandu mangrove wetland. Ecol. Eng. 2004, 23, 85-94.

5. Willis, J.M.; Hester, M.W.; Shaffer, G.P. A mesocosm evaluation of processed drill cuttings for wetland restoration. Ecol. Eng. 2005, 25, 41-50.

6. Lewis, R.R., III. Ecological engineering for successful management and restoration of mangrove forests. Ecol. Eng. 2005, 24, 403-418.

7. Zhou, G. Influences of tropical forest changes on environmental quality in Hainan province, P.R. of China. Ecol. Eng. 1995, 4, 223-229.

8. Blasco, F.; Saenger, P.; Janodet, E. Mangroves as indicators of costal change. Catena 1996, 27, 167-178.

9. Kathiresan, K.; Bingham, B.L. Biology of mangroves and mangrove ecosystems. Adv. Mar. Biol. 2001, 40, 81-251.

10. Dahdouh-Guebas, F.; Mathenge, C.; Kairo, J.G.; Koedam, N. Utilization of mangrove wood products around Mida Creek (Kenya) amongst subsistence and commercial users. Econ. Bot. 2000, 54, 513-527.

11. Ruiz-Luna, A.; Acosta-Velázquez, J.; Berlanga-Robles, C.A. On the reliability of the data of the extent of mangroves: A case study in Mexico. Ocean Coast. Manag. 2008, 51, 342-351.

12. Ruiz-Luna, A.; Berlanga-Robles, C.A. Land use, land cover changes and coastal lagoon surface reduction associated with urban growth in northwest Mexico. Landsc. Ecol. 2003, 18, 159-171.

13. Spalding, M.D.; Blasco, F.; Field, C.D. World Mangrove Atlas; The International Society for Mangrove Ecosystems: Okinawa, Japan, 1997; p. 178.

14. Alongi, D.M. Present state and future of the world's mangrove forests. Environ. Conserv. 2002, 29, 331-349.

15. Aizpuru, M.; Achard, F.; Blasco, F. Global Assessment of Cover Change of the Mangrove Forest Using Satellite Imagery at Medium to High Resolution; EEC Research Project No 15017-1999-05 FIED ISP FR; Joint Research Center: Ispra, Italy, 2000.

16. Blasco, F.; Aizpuru, M. Mangroves along the coastal stretch of the Bay of Bengal: Present status. Indian J. Mar. Sci. 2002, 31, 9-20.

17. Gao, J. A comparative study on spatial and spectral resolutions of satellite data mapping in mangrove forests. Int. J. Remote Sens. 1999, 20, 2823-2833.

18. Haito, H.; Bellan, M.F.; Al-Habshi, A.; Aizpuru, M.; Blasco, F. Mangrove research and coastal ecosystem studies with SPOT-4 HRVIR and TERRA ASTER in the Arabian Gulf. Int. J. Remote Sens. 2003, 24, 4073-4092.

19. Rasolofoharinoro, M.; Blasco, F.; Bellan, M.F.; Aizpuru, M.; Gauquelin, T.; Denis, J. A remote sensing based methodology for mangrove studies in Madagascar. Int. J. Remote Sens. 1998, 19, 1873-1886.

20. Green, E.; Mumby, P. Mapping mangroves. In Remote Sensing Handbook for Tropical Coastal Management; Edwards, A.J., Ed.; UNESCO: Paris, France, 2000; pp. 183-198.

21. Green, E.P.; Mumby, P.; Clark, C.D.; Mumby, P.J.: Edwards, A.J.; Ellis, A.C. Remote sensing techniques for mangrove mapping. Int. J. Remote Sens. 1998, 19, 935-956.

22. Green, E.P.; Mumby, P.J.; Edwards, A.J.; Clark, C.D.; Ellis, A.C. The assessment of mangrove area using high resolution multispectral airborne imagery. J. Coast. Res. 1998, 14, 433-443. 
23. Green, E.P.; Mumby, P.J.; Edwards, A.J.; Clark, C.D.; Ellis, A.C. Estimating leaf area index of mangroves from satellite data. Aquat. Bot. 1997, 58, 11-19.

24. Jensen, J.R.; Ramsey, E.; Davis, B.A.; Thoemke, C.W. The measurement of mangrove characteristics in south-west Florida using SPOT multispectral data. Geocarto Int. 1991, 2, 13-21.

25. Ramsey, E.W., III; Jensen, J.R. Remote sensing of mangrove wetlands: Relating canopy spectra to site-specific data. Photogramm. Eng. Remote Sensing 1996, 62, 939-948.

26. Allison, M.A.; Lee, M.T. Sediment exchange between Amazon mudbanks and shore-fringing mangroves in French Guiana. Mar. Geol. 2004, 208, 169-190.

27. Bird, M.; Chua, S.; Fifield, L.K.; Teh, T.S.; Lai, J. Evolution of the Sungei Buloh-Kranji mangrove coast, Singapore. Appl. Geogr. 2004, 24, 181-198.

28. Chen, T.S. A remote sensing imagery analysis for the Tatu esturary. Endem. Species Res. 2002, 4, 61-74.

29. Fromard, F.; Vega, C.; Proisy, C. Half a century of dynamic coastal change affecting mangrove shorelines of French Guiana. A case study based on remote sensing data analyses and field surveys. Mar. Geol. 2004, 208, 265-280.

30. Nakamura, F.; Kameyama, S.; Mizugaki, S. Rapid shrinkage of Kushiro Mire, the largest mire in Japan, due to increased sedimentation associated with land-use development in the catchment. Catena 2004, 55, 213-229.

31. Wang, Z.M.; Zhang, B.; Zhang, S.Q.; Li, X.Y.; Liu, D.W.; Song, K.S.; Li, J.P.; Li, F.; Duan, H.T. Changes of land use and of ecosystem service values in Sanjiang Plain, Northeast China. Environ. Monit. Assess. 2006, 112, 69-91.

32. Zhao, B.; Kreuter, U.; Li, B.; Ma, Z.J.; Chen, J.K.; Nakagoshi, N. An ecosystem service value assessment of land-use change on Chongming Island, China. Land Use Policy 2004, 21, 139-148.

33. Murray, M.R.; Zisman, S.A.; Furley, P.A.; Munro, D.M.; Gibson, J.; Ratter, J.; Bridgewater, S.; Minty, C.D.; Place, C.J. The mangroves of Belize: Part 1. Distribution, composition and classification. For. Ecol. Manag. 2003, 174, 265-279.

34. Ramírez-García, P.; López-Blanco, J.; Ocaña, D. Mangrove vegetation assessment in the Santiago River Mouth, Mexico, by means of supervised classification using Landsat TM imagery. For. Ecol. Manag. 1998, 105, 217-229.

35. Blasco, F.; Aizpuru, M.; Din Ndongo, D. Mangroves, Remote Sensing. In Encyclopedia of Coastal Science; Schwartz, M.L., Ed.; Springer Netherlands: Dordrecht, The Netherlands, 2005; pp. 614-617.

36. Soto-Jimenez, M.F.; Paez-Osuna, F. Distribution and normalization of heavy metal concentration in mangrove and lagoonal sediments from Mazatlan Harbor (SE Gulf of California). Estuar. Coast. Shelf Sci. 2001, 53, 259-274.

37. Ruiz-Luna, A.; Berlanga-Robles, C.A. Modifications in Coverage Patterns and Land Use around the Huizache-Caimanero Lagoon System, Sinaloa, Mexico: A Multi-temporal Analysis using LANDSAT Images. Estuar. Coast. Shelf Sci. 1999, 49, 37-44.

38. Alatorre, L.C.; Beguería, S. Identification of eroded areas using remote sensing in a badlands landscape on marls in the central Spanish Pyrenees. Catena 2009, 76, 182-190. 
39. Yoda, K.; Kira, T.; Ogawa, H.; Hozumi, K. Intraspecific competition among higher plants. IX. Self-thinning in overcrowded pure stands under cultivation and natural conditions. J. Biol. 1963, 14, 107-109.

40. Palá, V.; Pons, X. Incorporation of relief in polynomial-based geometric corrections. Photogramm. Eng. Remote Sensing 1996, 61, 935-944.

41. INEGI. National Institute of Statistic and Geography, Mexico. Available online: www.inegi.gob.mx (accessed on 18 July 2011).

42. Vermote, E.F.; Tanré, D.; Deuzé, J.L.; Herman, M.; Morcrette, J.J. Second simulation of the satellite signal in the solar spectrum, 6s: An overview. IEEE Trans. Geosci. Remote Sens. 1997, 35, 675-686.

43. Vicente-Serrano, S.M.; Peréz-Cabello, F.; Lasanta, T. Assessment of radiometric correction techniques in analyzing vegetation variability and change using time series of Landsat images. Remote Sens. Environ. 2008, 112, 3916-3934.

44. Cintron, G.; Lugo, A.E.; Pool, D.J.; Morris, G. Mangroves of arid environments in Puerto Rico and adjacent islands. Biotropica 1978, 10, 110-121.

45. Beguería, S. Identifying erosion areas at basin scale using remote sensing data and GIS. Int. J. Remote Sens. 2006, 20, 4585-4598.

46. Beguería, S. Validation and evaluation of predicitive models in hazard assessment and risk management. Nat. Hazards 2006, 37, 315-329.

47. Deleo, J.M. Receiver Operating Characteristic Laboratory (ROCLAB): Software for Developing Decision Strategies that Account for Uncertainty. In Proceedings of the Second International Symposium on Uncertainty Modelling and Analysis, College Park, MD, USA, 25-28 April 1993; pp. 318-325.

48. Fawcett, T. An introduction to ROC analysis. Pattern Recog. Lett. 2006, 27, 861-874.

49. Ripple, W.J. Landsat Thematic Mapper bands for characterizing fescue grass vegetation. Int. J. Remote Sens. 1985, 8, 1373-1384.

50. Onuf, C.P. Aspects of the biology of Salicornia Bigelovil Torr. in relation to a proposed restoration of a wind-tidal flat system on the south Texas, USA coast. Wetlands 2006, 26, 649-666.

(C) 2011 by the authors; licensee MDPI, Basel, Switzerland. This article is an open access article distributed under the terms and conditions of the Creative Commons Attribution license (http://creativecommons.org/licenses/by/3.0/). 